\title{
Clinical Trial Independent Data Monitoring Committee Correspondence
}

National Cancer Institute

\section{Source}

National Cancer Institute. Clinical Trial Independent Data Monitoring Committee

Correspondence. NCI Thesaurus. Code C115485.

Records that document the correspondence between a clinical trial, and the trial's Independent Data Monitoring Committee. 